\title{
Cost-effectiveness analysis of umeclidinium/ vilanterol for the management of patients with moderate to very severe COPD using an economic model
}

\author{
This article was published in the following Dove Press journal: \\ International Journal of COPD \\ 24 March 2017 \\ Number of times this article has been viewed
}

\author{
Michele R Wilson' \\ Jeetvan G Patel ${ }^{2,3}$ \\ Amber Coleman ${ }^{2}$ \\ Cheryl L McDade' \\ Richard H Stanford ${ }^{2}$ \\ Stephanie R Earnshaw' \\ 'RTI Health Solutions, Research \\ Triangle Park, NC, USA; ${ }^{2}$ GSK, \\ Research Triangle Park, NC, USA; \\ ${ }^{3}$ Amgen Inc., Thousand Oaks, CA, USA
}

Correspondence: Michele R Wilson RTI Health Solutions, 200 Park Offices Drive, PO Box 12194, Research

Triangle Park, NC 27709, USA

$\mathrm{Tel}+19195975116$

Fax +19195417222

Email mwilson@rti.org
Background: Bronchodilators such as long-acting muscarinic antagonists (LAMAs) and long-acting $\beta_{2}$-agonists (LABAs) are central to the pharmacological management of COPD. Dual bronchodilation with umeclidinium/vilanterol (UMEC/VI; $62.5 / 25 \mu \mathrm{g}$ ) is a novel LAMA/ LABA combination approved for maintenance treatment for patients with COPD.

Objective: The objective of this study was to assess the cost-effectiveness of maintenance treatment with UMEC/VI compared with tiotropium (TIO) $18 \mu \mathrm{g}$, open dual LAMA + LABA treatment, or no long-acting bronchodilator treatment in patients with moderate to very severe COPD.

Methods: A Markov model was developed to estimate the costs and outcomes associated with UMEC/VI treatment in patients with moderate to very severe COPD (GSK study number: HO-13-13411). Clinical efficacy, costs, utilities, and mortality obtained from the published literature were used as the model inputs. Costs are presented in US dollars based on 2015 prices. The model outputs are total costs, drug costs, other medical costs, number of COPD exacerbations, and quality-adjusted life-years (QALYs). Costs and outcomes were discounted at a 3\% annual rate. Incremental cost-effectiveness ratios were calculated. One-way and probabilistic sensitivity analyses were conducted to assess the effects of changing parameters on the uncertainty of the results.

Results: UMEC/VI treatment for moderate to very severe COPD was associated with lower lifetime medical costs $(\$ 82,344)$ compared with TIO $(\$ 88,822)$, open dual LAMA + LABA treatment $(\$ 114,442)$, and no long-acting bronchodilator $(\$ 86,751)$. Fewer exacerbations were predicted to occur with UMEC/VI treatment compared with no long-acting bronchodilator treatment. UMEC/VI provided an 0.11 and 0.25 increase in QALYs compared with TIO and no long-acting bronchodilator treatment, and as such, dominated these cost-effectiveness analyses. Sensitivity analyses confirmed that the results were robust.

Conclusion: The results from this model suggest that UMEC/VI treatment would be dominant compared with TIO and no long-acting bronchodilator treatment, and less costly than open dual LAMA + LABA treatment in patients with moderate to very severe COPD.

Keywords: umeclidinium, vilanterol, cost-effectiveness, tiotropium, COPD

\section{Introduction}

COPD is a highly prevalent, ${ }^{1,2}$ debilitating, chronic condition that has a significant impact on quality of life $^{3}$ and costs borne by health care systems. ${ }^{4}$ In $2010, \$ 32.1$ billion direct medical costs were estimated to be attributable to COPD and its sequelae 
in the USA and a further $\$ 3.9$ billion to absenteeism costs. ${ }^{5}$ Maintenance bronchodilator therapy is the foundation of stable COPD treatment, and combining bronchodilators is supported as a useful treatment option for patients with a higher symptom burden. ${ }^{2}$

The combination of the long-acting muscarinic antagonist (LAMA) umeclidinium (UMEC) with the long-acting $\beta_{2}$-agonist (LABA) vilanterol (VI) is an approved maintenance treatment for COPD in the USA, the EU, and several other countries. ${ }^{6-8}$ Treatment with UMEC/VI increases lung function compared with tiotropium (TIO) monotherapy or placebo and has a clinically acceptable safety profile; ${ }^{9-11}$ however, its cost-effectiveness remains unknown. A potential barrier to the use of dual bronchodilator therapy could be the cost and complexity of adding an additional inhaler to patients' treatments.

To address this, we examined the cost-effectiveness of UMEC/VI versus TIO, no long-acting bronchodilator treatment, and open dual (LAMA + LABA) bronchodilator treatment in patients with moderate to very severe COPD in the USA.

\section{Methods}

\section{Analytic framework}

A Markov model was developed with 1-year cycle times in which patients progressed through three COPD severity levels as defined by the 2013 COPD clinical guidelines. ${ }^{12}$ Severity of COPD was classified according to the predicted postbronchodilator forced expiratory volume in 1 second $\left(\mathrm{FEV}_{1}\right)$ of patients, as shown in Figure $1 .{ }^{12}$

Data from an initial mix of patients in different disease severity health states were entered into the Markov model (GSK study number: HO-13-13411). This mix was obtained from a prevalence study ${ }^{1}$ and from the Evaluation of COPD Longitudinally to Identify Predictive Surrogate Endpoints (ECLIPSE) observational study (NCT00292552). ${ }^{13}$ Upon entering into the model, patients were prescribed a maintenance COPD treatment plus usual care. Each year in the model, patients remained in their current disease severity health state or moved to the next more severe health state.

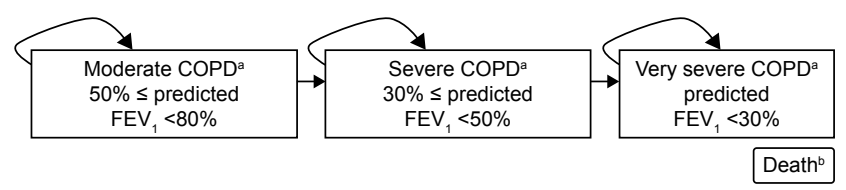

Figure I Structure of the decision model used.

Notes: ${ }^{a}$ Within the health states, patients may experience either a severe or a nonsevere exacerbation. 'beath could occur from any health status.

Abbreviation: $\mathrm{FEV}_{1}$, forced expiratory volume in I second.
Within a year, patients could also experience an exacerbation or remain event free (ie, with no exacerbation). Death could occur from any health state according to the natural progression of the disease. ${ }^{14}$

The perspective of the analysis was that of a third-party payer in the USA where only direct medical costs were considered. A 20-year time horizon was assessed. Costs and outcomes were discounted at 3\% per annum, and costs were reported in 2015 US dollars.

\section{Patient population}

Consistent with the patient populations studied in UMEC/VI clinical trials, ${ }^{9-11}$ patients included in this analysis were aged 40 years or older, had moderate to very severe COPD, and were eligible for maintenance treatment with LAMA/ LABA combination therapy. ${ }^{6}$ Additional eligibility criteria included current smokers or ex-smokers with a smoking history of $\geq 10$ pack-years, postalbuterol $\mathrm{FEV}_{1} /$ forced vital capacity $(\mathrm{FVC}) \leq 0.70, \mathrm{FEV}_{1} \leq 70 \%$ of predicted normal, and score of $\geq 2$ using the Modified Medical Research Council Dyspnea Scale. Patients with a history of asthma or previous use of UMEC and/or VI were excluded.

\section{Comparators}

The following treatment regimens were compared: UMEC/VI (62.5/25 $\mu \mathrm{g}$; delivering 55/22 $\mu \mathrm{g}$ administered once daily), TIO (18 $\mu \mathrm{g}$; delivering $10 \mu \mathrm{g}$ administered once daily), open dual LAMA + LABA therapy (TIO administered once daily and a LABA administered twice daily from separate inhalers), and no long-acting bronchodilator (where no such longacting COPD maintenance treatment was administered).

TIO was chosen as the primary comparator for UMEC/VI, because it is one of the recommended first-line maintenance treatments for patients with moderate to very severe COPD ${ }^{2}$ and one of the most commonly used long-acting bronchodilators in the USA and Canada for the treatment of patients with COPD. ${ }^{15,16}$

\section{Model inputs}

\section{Change in trough FEV, efficacy}

The model used 1) the improvement in lung function (ie, trough $\mathrm{FEV}_{1}$ ) in the first 24-26 weeks of treatment (Table 1), ${ }^{9-11,17}$ 2) patient characteristics, 3) average predicted $\mathrm{FEV}_{1}$, and 4) annual rate of decline as observed among patients in the different disease severity health states to estimate the transition probabilities between the disease severity levels. Transitions between patients' disease severity health states were based on the method described by Spencer et al, ${ }^{18}$ which used 
Table I Clinical efficacy, including change in trough $\mathrm{FEV}_{1}$, exacerbations, and AEs

\begin{tabular}{|c|c|c|c|}
\hline Parameter & Values & Source/assumption & \\
\hline \multicolumn{4}{|c|}{ Mean change in trough FEV in the first 24-26 weeks of treatment (L) } \\
\hline UMEC/VI & 0.200 & \multicolumn{2}{|c|}{ Decramer et al $(2014)^{9}$ and Maleki-Yazdi et al (20l4)" } \\
\hline TIO & 0.112 & \multicolumn{2}{|c|}{ Decramer et al (2014) ${ }^{9}$ and Maleki-Yazdi et al (2014)"1 } \\
\hline No long-acting bronchodilator ${ }^{\mathrm{a}}$ & 0.033 & \multirow{2}{*}{\multicolumn{2}{|c|}{$\begin{array}{l}\text { Jones }(2013)^{17} \text { and Donohue et al }(2013)::^{10} \text { the placebo arm in this study } \\
\text { was shown to have some effect on } \mathrm{FEV}_{1} \text {, believed to be due to short- } \\
\text { term treatment }\end{array}$}} \\
\hline & & & \\
\hline Open dual LAMA + LABA & 0.200 & \multicolumn{2}{|c|}{ Assumed same as UMEC/ $\mathrm{Vl}^{\mathrm{b}}$} \\
\hline \multicolumn{4}{|c|}{ Exacerbations per year (by disease severity) } \\
\hline \multicolumn{4}{|l|}{ Total } \\
\hline Moderate COPD & 0.85 & \multirow[t]{3}{*}{ Hurst et al $(2010)^{13}$} & \\
\hline Severe COPD & 1.34 & & \\
\hline Very severe COPD & 2.00 & & \\
\hline \multicolumn{4}{|l|}{ Severe } \\
\hline Moderate COPD & 0.11 & \multirow[t]{3}{*}{ Hurst et al $(2010)^{13}$} & \\
\hline Severe COPD & 0.25 & & \\
\hline Very severe COPD & 0.54 & & \\
\hline \multicolumn{4}{|l|}{ Nonsevere } \\
\hline Moderate COPD & 0.74 & \multirow[t]{3}{*}{ Hurst et al $(2010)^{13}$} & \\
\hline Severe COPD & 1.09 & & \\
\hline Very severe COPD & 1.46 & & \\
\hline \multicolumn{4}{|c|}{ AE rates (\%); 'Decramer et al (20 I 4), ${ }^{9}$ Donohue et al (20I3), ${ }^{10}$ Maleki-Yazdi et al (20I4)," and Celli et al $(20 \text { I4) })^{19}$} \\
\hline & UMEC/VI & TIO (absolute difference: & No long-acting bronchodilator \\
\hline & & UMEC/VI - TIO) & treatment (absolute difference: \\
\hline & & & UMEC/VI - no long-acting \\
\hline & & & bronchodilator) \\
\hline $\mathrm{N}$ & 1,296 & 874 & 555 \\
\hline Headache & 8.95 & $6.29(2.66)$ & $10.45(-1.50)$ \\
\hline Musculoskeletal (back) pain & 3.09 & $3.20(-0.11)$ & $3.60(-0.5 I)$ \\
\hline Nasopharyngitis & 7.87 & $7.21(0.66)$ & $8.65(-0.78)$ \\
\hline Upper respiratory tract infection & 2.31 & $2.97(-0.66)$ & $3.78(-1.47)$ \\
\hline
\end{tabular}

Notes: ${ }^{M}$ Mean change in $\mathrm{FEV}$, for no long-acting bronchodilator treatment compared with UMEC/VI was extracted from Donohue et al. ${ }^{10}$ bThis was one of the key assumptions made for this model. ' $A E s$ are not shown for open dual LAMA + LABA therapy as they were assumed to be the same as for UMEC/VI.

Abbreviations: AE, adverse event; $F E V_{1}$, forced expiratory volume in I second; LABA, long-acting $\beta_{2}$-agonist; LAMA, long-acting muscarinic antagonist; TIO, tiotropium; UMEC, umeclidinium; VI, vilanterol.

patients' average time in each health state (Supplementary materials and Tables S1-S4).

Changes in trough $\mathrm{FEV}_{1}$ at 24-26 weeks for the different treatments were obtained from three studies for UMEC/VI (NCT01316900 [GSK study number DB2113360], NCT01316913 [DB2113374], and NCT01777334 [ZEP117115] $)^{9,11}$ and one study for no long-acting bronchodilator (NCT01313650 [DB2113373]) ${ }^{10}\left(\right.$ Table 1) ${ }^{9-11,17}$. Within these trials, the patient populations and methods used to measure relative changes in trough $\mathrm{FEV}_{1}$ were similar. ${ }^{9-11}$ It was therefore assumed that the relative changes in trough $\mathrm{FEV}_{1}$ observed for UMEC/VI compared with TIO reported in the head-to-head trials ${ }^{9,11}$ could be compared with the change in trough $\mathrm{FEV}_{1}$ observed in the placebo-controlled trial. ${ }^{10}$ It was also assumed that the change in trough $\mathrm{FEV}_{1}$ was the same for the UMEC/VI and open dual LAMA + LABA therapies (Table 1) $)^{9-11,17}$. As the change in trough $\mathrm{FEV}_{1}$ for each maintenance treatment was greater versus no long-acting treatment, patients in these groups remained in less severe health states longer than patients on no longacting treatment.

\section{Exacerbations}

Exacerbations in this model were events that caused patients to seek health care. Patients could experience different levels of exacerbations or no exacerbations. Severe exacerbations were classified as events requiring hospitalization, and nonsevere exacerbations as events requiring a change in treatment such as systemic corticosteroids and/or antibiotics and/or contact with a health care provider. Patients were considered event free if they experienced no exacerbations.

Exacerbation risk was based on patient COPD severity and was obtained from the ECLIPSE study (Table 1). ${ }^{13}$

As a result, the impact that a treatment has on exacerbation was considered implicitly in the model. A treatment's direct impact on exacerbations was not modeled as the 
clinical studies reporting the treatment effects were not powered to do so.

\section{Adverse events (AEs)}

AEs not associated with discontinuation were accounted for within the model. Specifically, AEs that occurred in at least $3 \%$ of patients and those deemed to result in significant costs were identified. AE rates for each treatment option were estimated using pooled data from the comparative trials of UMEC/VI (Table 1), ${ }^{9-11,19}$ apart from the AE rates for open dual LAMA + LABA treatment that were assumed to be the same as UMEC/VI. It was also assumed that AEs occurred in year 1 of the model and subsequent AEs were accounted for in the discontinuation rates.

\section{Discontinuations}

Patients may discontinue treatment due to lack of efficacy and/or due to an occurrence of an intolerable AE. The clinical impact of discontinuations was captured in the clinical efficacy input and was assumed to be similar for open dual LAMA + LABA and UMEC/VI treatment. Patients who discontinued due to lack of efficacy were reverted to no treatment and were assumed to move to standard care (defined as no treatment with UMEC/VI) as seen in the trials. The cost of the respective treatments was reduced. However, additional drug costs were not captured. As a result, results may be considered to be conservative.

\section{Mortality}

Deaths (related to COPD and other causes) were considered in the model. Age-specific all-cause mortality was obtained from the US National Vital Statistics. ${ }^{20}$ COPD-specific death was incorporated by applying relative risks for moderate COPD (relative risk $=1.4$ ) and severe and very severe COPD (relative risk =2.6) from Shavelle et al. ${ }^{14}$ It was assumed that COPDrelated mortality was only based on disease severity.

\section{Drug costs}

All costs included in the model were in US dollars and based on 2015 data. Estimations of monthly prescription costs were based on the recommended dosing of each treatment. ${ }^{6,21}$ No long-acting bronchodilator treatment was assumed to be the cost of the short-acting bronchodilators ipratropium/albuterol $\left(\right.$ Combivent $\left.^{\circledR}\right) .{ }^{22}$ Open dual LAMA + LABA treatment was assumed to include the cost of TIO and the estimated average cost of salmeterol and formoterol administered twice daily. All drug costs were obtained from Medi-Span 2.0 (Table 2). ${ }^{23}$ Patients were assumed to be fully compliant with UMEC/VI or TIO treatments.

\section{Add-on therapy}

Add-on therapy was considered in the model to account for the additional costs incurred by patients who progress to triple therapy. The additional costs were for fluticasone propionate/salmeterol $\left(\right.$ Advair $\left.^{\circledR}\right)$ for patients in the TIO and no long-acting bronchodilation groups and also for fluticasone for UMEC/VI and open dual LAMA + LABA therapy groups. It should be noted that the percentage of patients who progressed to triple therapy was assumed to be related to disease severity and not to specific treatments, with the percentages used within this assumption obtained from a treatment pattern analysis (Table 2, GSK data on file).

\section{Additional medical costs}

Medical costs (other than those detailed previously) were also included and were assumed to be specific to exacerbations. These medical costs included inpatient, emergency room, outpatient, and "other" medical costs. "Other" medical costs were those not previously covered, such as home visits and skilled nursing facility services. Total medical costs for a severe exacerbation, nonsevere exacerbation, and no exacerbation were estimated according to $\mathrm{Yu}$ et al. ${ }^{24}$ The costs included those of the index exacerbation visit and those of any subsequent treatments. The costs of an AE resulting from the COPD maintenance treatments (the cost per AE assumed one physician visit and antibiotics as applicable; Table 2$)^{25-27}$ were also considered within the model.

\section{Utility weights}

The annual utility weights used within the model were derived from those previously published and were related to disease severity and exacerbation events (Table 2). ${ }^{18}$ Severe exacerbations and nonsevere exacerbations were assumed to have a duration of 28 days and 10.5 days, respectively. These utility values were used to estimate quality-adjusted life-years (QALYs) by multiplying the number of accrued life-years within a particular health state by the disease severity's utility weight.

\section{Model calculations}

The following outputs were estimated by the model: total costs, drug costs, other medical costs, number of exacerbations (total, nonsevere, and severe), life-years, and QALYs.

The cost-effectiveness of UMEC/VI versus each comparator was determined by calculating the incremental total cost per life-year or QALY gained: $\left(\mathrm{C}_{\mathrm{i}}-\mathrm{C}_{\mathrm{s}}\right) /\left(\mathrm{E}_{\mathrm{i}}-\mathrm{E}_{\mathrm{s}}\right)$, where $\mathrm{C}_{\mathrm{i}}$ is the cost accrued by the treatment of interest, $\mathrm{C}_{\mathrm{s}}$ is the cost accrued by the status quo treatment, $\mathrm{E}_{\mathrm{i}}$ is the effectiveness 
Table 2 Costs included as model inputs and the utility values for COPD severity and exacerbation severity

\begin{tabular}{|c|c|c|c|}
\hline Parameter & Value & \multicolumn{2}{|l|}{ Source/assumption } \\
\hline Exacerbation costs & Quarterly costs & & \\
\hline Severe exacerbation & $\$ 8,116.88$ & \multicolumn{2}{|c|}{ Yu et al $(20 \mathrm{II})^{24}$ and US BLS $(20 \mathrm{I} 5)^{27}$} \\
\hline Nonsevere exacerbation & $\$ 1,40 \mathrm{I} .56$ & \multicolumn{2}{|c|}{ Yu et al $(201 \mathrm{I})^{24}$ and US BLS $(2015)^{27}$} \\
\hline No exacerbation & $\$ 527.76$ & \multicolumn{2}{|c|}{ Yu et al $(20 \mathrm{II})^{24}$ and US BLS $(2015)^{27}$} \\
\hline$\overline{A E}$ & $\begin{array}{l}\text { Costs }^{\mathrm{a}}(\text { per } \\
\text { reported AE) }\end{array}$ & & \\
\hline Headache & $\$ 73.99$ & \multicolumn{2}{|c|}{ Physician visit at $\$ 73.99$ (RBRVS, [Ingenix, 20I3] $\left.{ }^{26}\right)$; US BLS $(2015)^{27}$} \\
\hline Musculoskeletal (back) pain & $\$ 73.99$ & \multirow{2}{*}{\multicolumn{2}{|c|}{ 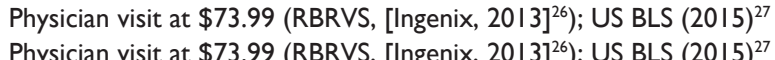 }} \\
\hline Nasopharyngitis & $\$ 73.99$ & & \\
\hline Upper respiratory tract infection & $\$ 75.36$ & \multicolumn{2}{|c|}{ Physician visit at $\$ 73.99$ (RBRVS, [Ingenix, 2013] $]^{26}$ ) and penicillin } \\
\hline & & \multicolumn{2}{|c|}{$\begin{array}{l}V \text { antibiotic treatment at } \$ 13.00 \text { applied to } 10 \% \text { of patients with } \\
\text { strep-positive diagnosis }(C D C) ;{ }^{25} \text { US BLS }(2015)^{27}\end{array}$} \\
\hline Drug costs & $\begin{array}{l}\text { Monthly prescription } \\
\text { costs (WAC) }\end{array}$ & & \\
\hline UMEC/VI & $\$ 297.81$ & \multicolumn{2}{|l|}{ Medi-Span $(2015)^{23}$} \\
\hline TIO & $\$ 315.68$ & \multicolumn{2}{|l|}{ Medi-Span $(2015)^{23}$} \\
\hline No long-acting bronchodilator & $\$ 295.71$ & \multicolumn{2}{|c|}{ Assumed price of ipratropium/albuterol ${ }^{23}$} \\
\hline LAMA & $\$ 315.68$ & \multicolumn{2}{|l|}{ Assumed price of $\mathrm{TIO}^{23}$} \\
\hline LABA & $\$ 261.74$ & \multicolumn{2}{|c|}{ Assumed price of salmeterol and formotero ${ }^{23}$} \\
\hline \multicolumn{4}{|l|}{ Add-on drug costs } \\
\hline ICS & $\$ 179.70$ & \multicolumn{2}{|c|}{$\begin{array}{l}\text { Assumed price of fluticasone propionate; applied to UMEC/VI and } \\
\text { open dual after I year of primary treatment }\end{array}$} \\
\hline ICS/LABA & $\$ 309.84$ & \multicolumn{2}{|c|}{$\begin{array}{l}\text { Assumed price of fluticasone propionate/salmeterol; applied to TIO } \\
\text { and no long-acting bronchodilator after I year of primary treatment }\end{array}$} \\
\hline Add-on uptake & $\%$ & & \\
\hline Moderate COPD & 27 & \multicolumn{2}{|l|}{ GSK, data on file } \\
\hline Severe COPD & 40 & & \\
\hline Very severe COPD & 45 & & \\
\hline \multirow[t]{2}{*}{ Disease severity } & Utility (SE) ${ }^{\mathrm{b}}$ & \multicolumn{2}{|c|}{ By exacerbation: mean modeled utility $(\mathrm{SE})^{\mathrm{b}}$} \\
\hline & & $\begin{array}{l}\text { Requiring primary care } \\
\text { treatment with oral } \\
\text { corticosteroids and/or } \\
\text { antibacterials (nonsevere) }\end{array}$ & $\begin{array}{l}\text { Requiring hospital } \\
\text { admission (severe) }\end{array}$ \\
\hline Moderate COPD & $0.810(0.02)$ & $0.720(0.02)$ & $0.519(0.02)$ \\
\hline Severe COPD & $0.720(0.03)$ & $0.658(0.03)$ & $0.447(0.07)$ \\
\hline Very severe COPD & $0.670(0.05)$ & $0.475(0.05)$ & $0.408(0.05)$ \\
\hline
\end{tabular}

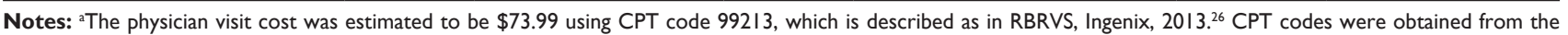
American Medical Association (2013). ${ }^{39}$ bisease severity and exacerbation-specific utilities were derived by Spencer (2005) et al. ${ }^{18}$ Costs are presented in US dollars based on 2015 prices.

Abbreviations: AE, adverse event; BLS, Bureau of Labor Statistics; CDC, Centers for Disease Control and Prevention; CPT, current procedural terminology; ICS, inhaled corticosteroids; LABA, long-acting $\beta_{2}$-agonist; LAMA, long-acting muscarinic antagonist; RBRVS, Resource Based Relative Value Scale; SE, standard error; TIO, tiotropium; UMEC, umeclidinium; VI, vilanterol; WAC, wholesale acquisition cost.

accrued by the treatment of interest (life-year or QALY), and $\mathrm{E}_{\mathrm{s}}$ is the effectiveness accrued by the status quo treatment (life-year or QALY); all over a lifetime horizon. Cost and health outcomes were discounted at a $3 \%$ rate per year.

The effect of changing parameters was examined in one-way sensitivity analyses to test the robustness of the model assumptions and specific parameters. The results of sensitivity analysis for each input were ranked from most sensitive to least sensitive and plotted on tornado diagrams, with the 15 most sensitive parameters presented.
Probabilistic sensitivity analyses (second-order Monte Carlo simulation), in which all parameters in the model were varied at the same time, were also performed. Analyses were run 10,000 times to capture stability in the results for each relevant scenario and presented using scatter plots.

\section{Results \\ Base-case analysis}

Treatment of patients with moderate to very severe COPD with UMEC/VI resulted in total remaining lifetime medical 
costs of $\$ 82,344$ compared with $\$ 88,822$ for TIO, $\$ 114,442$ for open dual LAMA + LABA treatment, and $\$ 86,751$ for no long-acting bronchodilator treatment (Table 3). Patients treated with UMEC/VI also experienced fewer exacerbations (due to initial improvements in lung function) compared with patients receiving no long-acting bronchodilator treatment.

Due to the assumptions used in the model, patients receiving UMEC/VI and open dual LAMA + LABA treatment experienced the same total life-years and QALYs. However, patients treated with UMEC/VI gained 0.16 life-years and 0.11 QALYs compared with TIO treatment and 0.35 life-years and 0.25 QALYs compared with no long-acting bronchodilator treatment. As UMEC/VI treatment was also less costly and was associated with fewer exacerbations compared with both TIO and no long-acting bronchodilator treatment, it was dominant to both (Table 3).

\section{One-way sensitivity analyses}

One-way sensitivity analyses showed that UMEC/VI treatment remained the dominant treatment compared with TIO and no long-acting bronchodilator treatment within the range of uncertainty applied to all variables in the model. UMEC/VI also had lower total costs compared with open dual LAMA + LABA within the range of uncertainty for all variables, mainly due to a lower acquisition cost.

\section{Probabilistic sensitivity analyses}

The probabilistic sensitivity analyses demonstrated that UMEC/VI was dominant $81.5 \%$ of the time, was not dominant but was cost-effective (incremental cost per QALY $<\$ 50,000$ ) $13.8 \%$ of the time, and was cost-effective $95.3 \%$ of the time compared with TIO (Figure 2A). Compared with no bronchodilator treatment, UMEC/VI was dominant $71.1 \%$ of the time, was not dominant but was cost-effective $27.8 \%$ of the time, and was cost-effective $98.9 \%$ of the time (Figure 2B). The safety and efficacy of open dual LAMA + LABA was assumed to be the same as UMEC/VI making a probabilistic sensitivity analysis for this particular comparison unnecessary.

\section{Discussion}

This analysis estimated the cost-effectiveness of UMEC/VI compared with other bronchodilator treatments for patients with moderate to very severe COPD and included a comparator of no long-acting bronchodilator treatment in which only short-acting rescue medication was permitted. In the basecase analysis, UMEC/VI was found to be dominant compared with TIO and no long-acting bronchodilator treatment. Furthermore, when UMEC/VI was compared with open dual LAMA + LABA treatment, both were assumed to have the same efficacy, but UMEC/VI was found to be less costly. Sensitivity analyses demonstrated that all cost-effectiveness findings were robust. Future analyses could investigate the cost-effectiveness of UMEC/VI compared with other closed dual bronchodilator treatments (eg, QVA149).

Since the approval of TIO as the first LAMA for the treatment of patients with COPD, several cost-effectiveness studies have been completed with different comparators. ${ }^{28-32}$ In this study, TIO cost more than no long-acting bronchodilation treatment but had an increased QALY of 0.14. An improvement in QALYs on TIO treatment has been reported in other studies comparing TIO with other treatments in COPD (0.051-0.15 QALYs), ${ }^{28-32}$ supporting the model assumptions used.

A strength of this analysis is that it incorporated progression to triple therapy (inhaled corticosteroids [ICS] +

Table 3 Base-case analysis results over a lifetime horizon

\begin{tabular}{|c|c|c|c|c|}
\hline Parameter & UMEC/VI & TIO & $\begin{array}{l}\text { No long-acting } \\
\text { bronchodilator }\end{array}$ & $\begin{array}{l}\text { Open dual } \\
\text { LAMA + LABA }\end{array}$ \\
\hline \multicolumn{5}{|l|}{ Costs } \\
\hline Drug costs & $\$ 40,229$ & $\$ 46,342$ & $\$ 43,715$ & $\$ 72,327$ \\
\hline Other medical costs & $\$ 42,115$ & $\$ 42,480$ & $\$ 43,036$ & $\$ 42,115$ \\
\hline Total costs & $\$ 82,344$ & $\$ 88,822$ & $\$ 86,75 \mathrm{I}$ & $\$ 114,442$ \\
\hline \multicolumn{5}{|l|}{ Number of exacerbations } \\
\hline Nonsevere & 10.866 & 10.938 & 11.045 & 10.866 \\
\hline Severe & 2.347 & 2.433 & 2.552 & 2.347 \\
\hline Total exacerbations & 13.214 & $|3.37|$ & 13.597 & 13.214 \\
\hline Life-years & 11.843 & 11.687 & 11.493 & 11.843 \\
\hline QALYs & 7.304 & 7.195 & 7.055 & 7.304 \\
\hline \multicolumn{5}{|c|}{ Incremental cost-effectiveness ratio } \\
\hline Cost per life-year gained & - & UMEC/VI dominates & UMEC/VI dominates & Not defined ${ }^{a}$ \\
\hline Cost per QALY gained & - & UMEC/VI dominates & UMEC/VI dominates & Not defined ${ }^{a}$ \\
\hline
\end{tabular}

Notes: ancremental cost-effectiveness ratio not defined as the effectiveness of open dual LAMA + LABA was assumed to be the same as UMEC/VI. Costs are presented in US dollars based on 2015 prices.

Abbreviations: LABA, long-acting $\beta_{2}$-agonist; LAMA, long-acting muscarinic antagonist; QALY, quality-adjusted life-year; TIO, tiotropium; UMEC, umeclidinium; VI, vilanterol. 
A

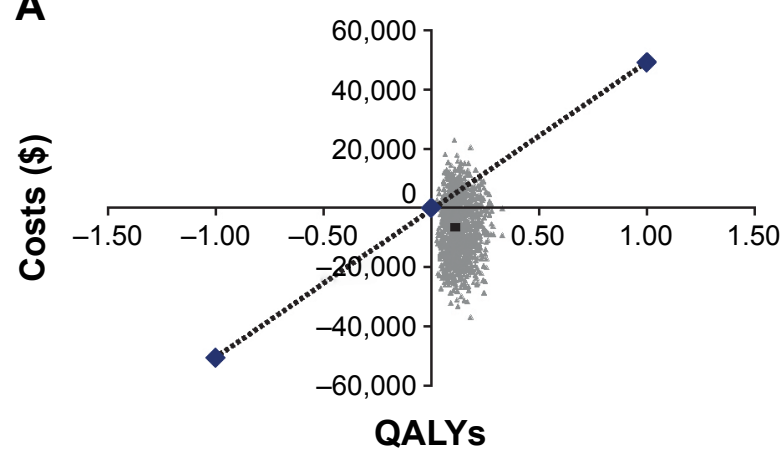

B

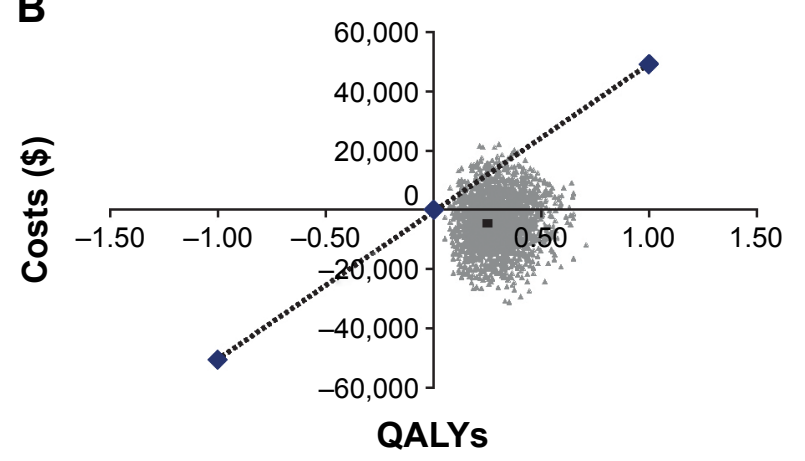

A Simulation runs

Figure 2 Cost-effectiveness of UMEC/VI treatment in patients with moderate to very severe COPD: probabilistic sensitivity analyses (A) UMEC/VI compared with TIO and (B) UMEC/VI compared with no long-acting bronchodilator.

Note: Costs are presented in US dollars based on 2015 prices.

Abbreviations: CE, cost-effectiveness; ICER, incremental cost-effectiveness ratio; QALY, quality-adjusted life-year; TIO, tiotropium; UMEC, umeclidinium; VI, vilanterol.

LAMA + LABA) for patients with COPD. This progression was based on disease severity and not specific treatments. A study in the UK found that patients with COPD often progress quickly to triple therapy ${ }^{33}$ and a second study in Japan found that more than half of patients who progress to triple therapy do so because of the need for additional symptom improvement. ${ }^{34}$ Progression to triple therapy incurs additional drug costs for COPD treatment, which this model accounted for in all treatment arms. Therefore, the reported cost-effectiveness for UMEC/VI includes this important aspect of COPD treatment.

A limitation of the study is that no formal statistical adjustments were made for the efficacy data of the treatments considered in this analysis, because of limited data on $\mathrm{FEV}_{1}$, comparative exacerbations, and treatment-related and exacerbation-related mortality. However, the sensitivity analysis that varied these parameters in the model showed that UMEC/VI remained cost-effective irrespective of variation in efficacy parameters.

Previous studies have shown that the major economic impact of maintenance treatment for COPD was in reducing exacerbations. ${ }^{29,31,32}$ While in this model, data were used from the ECLIPSE study ${ }^{13}$ that related $\mathrm{FEV}_{1}$ status to frequency of exacerbation events, other factors are also known to impact on exacerbation rate such as prior exacerbation history and heartburn. ${ }^{13}$ Furthermore, though disease severity has often been assessed using $\mathrm{FEV}_{1}$ performance in the past, recent clinical developments indicate that many other disease characteristics should be considered when assessing COPD severity. These factors were not directly accounted for in the model, and the analysis may need adjusting in the future once further data are available.
Another limitation is that COPD-related mortality was assumed to be disease severity specific and only indirectly accounted for treatment and exacerbation status, which is not necessarily the case and may have impacted the outcomes. ${ }^{35,36}$ Soler-Cataluna et $\mathrm{al}^{35}$ demonstrated that mortality is correlated with increasing severe exacerbations. However, as the impact of UMEC/VI on exacerbations has not yet been fully determined, ${ }^{9}$ this could not be fully included in the current model. Inclusion of treatment-specific impact on exacerbations and the associated mortality risk for exacerbations could affect the results, but it is unclear in which direction the effect would be without observing the exacerbation data for UMEC/VI. However, the data used within the model were the most accurately available at the time the analysis was undertaken and mortality was included. Finally, the assumption that patients would be fully compliant with the prescribed treatment regimens is unlikely to be true. While adherence with a once-daily TIO regimen is known to be high, ${ }^{37}$ it has not yet been directly evaluated with once-daily UMEC/VI. Adherence is likely to be similar as both treatments are once-daily inhalers, so it is unlikely to have an impact on the cost-effectiveness of UMEC/VI over TIO. Adherence to these once-daily LAMA treatments is likely to be much higher compared with adherence to any open dual regimen, as found in the recent real-world study comparing once-daily TIO with twice-daily budesonide/formoterol. ${ }^{38}$

\section{Conclusion}

The results from this model suggest that UMEC/VI treatment would be dominant compared with TIO and no long-acting bronchodilator treatment and be less costly than open dual LAMA + LABA treatment in patients with moderate to very 
severe COPD. Compared with TIO and no long-acting bronchodilator treatment, UMEC/VI was associated with fewer exacerbations as well as gains in life-years and QALYs.

\section{Acknowledgments}

GSK funded this study (study number HO-13-13411). Editorial assistance was provided by Gillian Groeger, $\mathrm{PhD}$, Fishawack Indicia Ltd (UK), which was funded by GSK.

\section{Author contributions}

MRW, JGP, AC, CLM, RHS, and SRE contributed to the concept and design of this study and undertook data analysis and interpretation. All authors contributed toward data analysis, drafting and critically revising the paper and agree to be accountable for all aspects of the work.

\section{Disclosure}

MRW, CLM, and SRE are employees of RTI Health Solutions, an independent contract research organization that has received funding from GSK for this and other studies and from other pharmaceutical companies that market drugs for the treatment of patients with COPD and other medical conditions. AC and RHS are employees of GSK and holders of GSK stock. JGP was an employee of GSK and holder of GSK stock at the time of the study. JGP is now employed by Amgen. The authors report no other conflicts of interest in this work.

\section{References}

1. Buist AS, McBurnie MA, Vollmer WM, et al; BOLD Collaborative Research Group. International variation in the prevalence of COPD (the BOLD Study): a population-based prevalence study. Lancet. 2007; 370(9589):741-750.

2. GOLD [homepage on the Internet]. Global strategy for the diagnosis, management and prevention of chronic obstructive pulmonary disease; 2015. Available from: http://www.goldcopd.com/. Accessed March 2015.

3. Nagai K, Makita H, Suzuki M, et al; Hokkaido COPD Cohort Study Investigators. Differential changes in quality of life components over 5 years in chronic obstructive pulmonary disease patients. Int J Chron Obstruct Pulmon Dis. 2015;10:745-757.

4. Dalal AA, Liu F, Riedel AA. Cost trends among commercially insured and Medicare Advantage-insured patients with chronic obstructive pulmonary disease: 2006 through 2009. Int J Chron Obstruct Pulmon Dis. 2011;6:533-542.

5. Ford ES, Murphy LB, Khavjou O, Giles WH, Holt JB, Croft JB. Total and state-specific medical and absenteeism costs of COPD among adults aged $>/=18$ years in the United States for 2010 and projections through 2020. Chest. 2015;147(1):31-45.

6. GSK. ANORO ${ }^{\text {TM }}$ ELLIPTA $^{\circledR}$ [prescribing information]. 2014. Available from: https://www.gsksource.com/gskprm/htdocs/documents/ANOROELLIPTA-PI-MG.PDF. Accessed June 2015.

7. GSK [webpage on the Internet]. ANORO ${ }^{\text {TM }}$ ELLIPTA $^{\circledR}$ summary of product characteristics; 2014. Available from: http://www.medicines. org.uk/emc/medicine/28949\#INDICATIONS. Accessed June 2015.
8. Blair HA, Deeks ED. Umeclidinium/vilanterol: a review of its use as maintenance therapy in adults with chronic obstructive pulmonary disease. Drugs. 2015;75(1):61-74.

9. Decramer M, Anzueto A, Kerwin E, et al. Efficacy and safety of umeclidinium plus vilanterol versus tiotropium, vilanterol, or umeclidinium monotherapies over 24 weeks in patients with chronic obstructive pulmonary disease: results from two multicentre, blinded, randomised controlled trials. Lancet Respir Med. 2014;2(6):472-486.

10. Donohue JF, Maleki-Yazdi MR, Kilbride S, Mehta R, Kalberg C, Church A. Efficacy and safety of once-daily umeclidinium/vilanterol 62.5/25 mcg in COPD. Respir Med. 2013;107(10):1538-1546.

11. Maleki-Yazdi MR, Kaelin T, Richard N, Zvarich M, Church A. Efficacy and safety of umeclidinium/vilanterol $62.5 / 25 \mathrm{mcg}$ and tiotropium $18 \mathrm{mcg}$ in chronic obstructive pulmonary disease: results of a 24-week, randomized, controlled trial. Respir Med. 2014;108(12): 1752-1760.

12. GOLD. Global strategy for the diagnosis, management and prevention of chronic obstructive pulmonary disease. 2013. Available from: http:// www.atsjournals.org/doi/abs/10.1164/rccm.201204-0596PP. Accessed February 2017.

13. Hurst JR, Vestbo J, Anzueto A, et al; Evaluation of COPD Longitudinally to Identify Predictive Surrogate Endpoints (ECLIPSE) Investigators. Susceptibility to exacerbation in chronic obstructive pulmonary disease. N Engl J Med. 2010;363(12):1128-1138.

14. Shavelle RM, Paculdo DR, Kush SJ, Mannino DM, Strauss DJ. Life expectancy and years of life lost in chronic obstructive pulmonary disease: findings from the NHANES III Follow-up Study. Int J Chron Obstruct Pulmon Dis. 2009;4:137-148.

15. Diette GB, Dalal AA, D'Souza AO, Lunacsek OE, Nagar SP. Treatment patterns of chronic obstructive pulmonary disease in employed adults in the United States. Int J Chron Obstruct Pulmon Dis. 2015;10: 415-422.

16. Green ME, Natajaran N, O'Donnell DE, et al. Chronic obstructive pulmonary disease in primary care: an epidemiologic cohort study from the Canadian Primary Care Sentinel Surveillance Network. CMAJ Open. 2015;3(1):E15-E22.

17. Jones C. ANORO ${ }^{\mathrm{TM}}$ ELLIPTA $^{\mathrm{TM}}$ Umeclidinium/Vilanterol Inhalation Powder 62.5/25 mcg; 2013. Available from: http://www.fda. gov/downloads/AdvisoryCommittees/CommitteesMeetingMaterials/ Drugs/Pulmonary-AllergyDrugsAdvisoryCommittee/UCM368638. pdf. Accessed June 2015.

18. Spencer M, Briggs AH, Grossman RF, Rance L. Development of an economic model to assess the cost effectiveness of treatment interventions for chronic obstructive pulmonary disease. Pharmacoeconomics. 2005;23(6):619-637.

19. Celli B, Crater G, Kilbride S, et al. Once-daily umeclidinium/ vilanterol 125/25 mcg in COPD: a randomized, controlled study. Chest. 2014;145(5):981-991.

20. Kochanek KD, Xu J, Murphy SL, Minino AM, Kung HC. Deaths: final data for 2009. Natl Vital Stat Rep. 2011;60(3):1-116.

21. Boehringer Ingelheim. SPIRIVA ${ }^{\circledR}$ HandiHaler ${ }^{\circledR}$ [prescribing information]. 2014. Available from: http://bidocs.boehringer-ingelheim. com/BIWebAccess $/$ ViewServlet.ser?docBase=renetnt $\&$ folder Path=/Prescribing+Information/PIs/Spiriva/Spiriva.pdf. Accessed September 2015.

22. Boehringer Ingelheim. Combivent ${ }^{\circledR}$ [prescribing information]. 2014. Available from: http://bidocs.boehringer-ingelheim.com/BIWebAccess/ ViewServlet.ser? docBase=renetnt $\&$ folderPath $=/$ Prescribing + Information/PIs/Combivent+Respimat/CMVTRSPT.pdf. Accessed September 2015.

23. Wolters Kluwer [webpage on the Internet]. Medi-Span ${ }^{\circledR} 2.0$ Price Rx Electronic Version; 2015. Indianapolis, IN: Wolters Kluwer. Available from: https://pricerx.medispan.com/. Accessed February 8, 2016.

24. Yu AP, Yang H, Wu EQ, Setyawan J, Mocarski M, Blum S. Incremental third-party costs associated with COPD exacerbations: a retrospective claims analysis. J Med Econ. 2011;14(3):315-323. 
25. Centers for Disease Control and Prevention [webpage on the Internet]. Adult Appropriate Antibiotic Use Summary: Physician Information Sheet. Available from: http://www.cdc.gov/getsmart/community/ materials-references/print-materials/hcp/adult-approp-summary.html. Accessed September 2015.

26. Ingenix. The Essential RBRVS (2013): A Comprehensive Listing of RBRVS Values for CPT and HCPCS Codes. New York, NY: St. Anthony Publishing; 2013.

27. US Bureau of Labor Statistics. US Department of Labor [webpage on the Internet]. US city average, not seasonally adjusted medical care. Available from: http://data.bls.gov/PDQ/outside.jsp? survey=cu. Accessed October 2015.

28. Hettle R, Wouters H, Ayres J, et al. Cost-utility analysis of tiotropium versus usual care in patients with COPD in the UK and Belgium. Respir Med. 2012;106(12):1722-1733.

29. Hoogendoorn M, Kappelhoff BS, Overbeek JA, Wouters EF, Rutten-van Molken MP. Which long-acting bronchodilator is most cost-effective for the treatment of COPD? Neth J Med. 2012;70(8): 357-364.

30. Oostenbrink JB, Rutten-van Molken MP, Monz BU, FitzGerald JM. Probabilistic Markov model to assess the cost-effectiveness of bronchodilator therapy in COPD patients in different countries. Value Health. 2005;8(1):32-46.

31. Rutten-van Molken MP, Oostenbrink JB, Miravitlles M, Monz BU. Modelling the 5-year cost effectiveness of tiotropium, salmeterol and ipratropium for the treatment of chronic obstructive pulmonary disease in Spain. Eur J Health Econ. 2007;8(2):123-135.
32. Eklund O, Afzal F, Borgstrom F. Cost-effectiveness of tiotropium versus usual care and glycopyrronium in the treatment of chronic obstructive pulmonary disease in Sweden. Cost Eff Resour Alloc. 2015;13:13.

33. Wurst KE, Punekar YS, Shukla A. Treatment evolution after COPD diagnosis in the UK primary care setting. PLoS One. 2014;9(9):e105296.

34. Miyazaki M, Nakamura H, Takahashi S, et al; Keio COPD Comorbidity Research (K-CCR) Group. The reasons for triple therapy in stable COPD patients in Japanese clinical practice. Int J Chron Obstruct Pulmon Dis. 2015;10:1053-1059.

35. Soler-Cataluna JJ, Martinez-Garcia MA, Roman Sanchez P, Salcedo E, Navarro M, Ochando R. Severe acute exacerbations and mortality in patients with chronic obstructive pulmonary disease. Thorax. 2005; 60(11):925-931.

36. Hoogendoorn M, Feenstra TL, Asukai Y, et al. Cost-effectiveness models for chronic obstructive pulmonary disease: cross-model comparison of hypothetical treatment scenarios. Value Health. 2014;17(5): 525-536.

37. Huurne KK, Movig K, van der Valk P, van der Palen J, Brusse-Keizer M Differences in adherence to common inhaled medications in COPD COPD. 2015;12(6):643-648.

38. Trudo F, Kern DM, Davis JR, et al. Comparative effectiveness of budesonide/formoterol combination and tiotropium bromide among COPD patients new to these controller treatments. Int J Chron Obstruct Pulmon Dis. 2015;10:2055-2066.

39. American Medical Association (AMA). Current Procedural Terminology (CPT). Chicago, IL: AMA Press; 2013. 


\section{Supplementary materials Methods}

Estimates of disease transitions were based on age, average height, percentage of the COPD population that was female, average percentage predicted forced expiratory volume in 1 second $\left(\mathrm{FEV}_{1}\right)$ among patients in the health state at start of model, average predicted normal $\mathrm{FEV}_{1}$, and annual rate of decline as observed among patients in the different disease severity health states in the ECLIPSE study. Reference equations were also used to estimate predicted normal $\mathrm{FEV}_{1}$ in males and females (included subsequently).

To calculate disease progression transition probabilities, the method detailed in Spencer et $\mathrm{al}^{1}$ was followed (Tables S1-S4).

- $\mathrm{T}=\left(\right.$ predFEV $_{1} \times($ gamma - tau $\left.)\right) /($ delta - tau $\times$ beta $)$

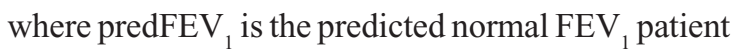
population, gamma is the percentage that actual $\mathrm{FEV}_{1}$ at baseline is of predicted normal $\mathrm{FEV}_{1}$, delta is the annual decline in lung function in patients with COPD, $\mathrm{T}$ is the time (in years) from when patients start in a health state until patients change to a new health state, tau is the percentage of predicted $\mathrm{FEV}_{1}$ threshold at which patients enter a new health state, beta is the rate of decline for a normal patient without COPD.

The following National Health and Nutrition Examination Survey/Hankinson reference equation was also used: ${ }^{2}$

- Predicted $\mathrm{FEV}_{1} \%$ = predicted $\mathrm{FEV}_{1} /$ predicted forced vital capacity (FVC)

Predicted FVC men, age to 19

$=-0.2584-0.20415 \times$ Age +0.010133

$\times$ Age $\times$ Age $+0.00018642 \times$ Height $($ in $\mathrm{cm})$

$\times$ Height (in $\mathrm{cm})$

Predicted FVC men, age 20+

$=-0.1933+0.00064 \times$ Age -0.000269

$\times$ Age $\times$ Age $+0.00018642 \times$ Height $($ in $\mathrm{cm})$

$\times$ Height $($ in $\mathrm{cm})$
Predicted FVC women

$$
\begin{aligned}
& =-0.3560+0.01870 \times \text { Age }-0.000382 \times \text { Age } \\
& \times \text { Age }+0.00014815 \times \text { Height }(\text { in } \mathrm{cm}) \\
& \times \text { Height (in } \mathrm{cm}) \\
& \text { Predicted } \mathrm{FEV}_{1} \text { men, age to } 19 \\
& =-0.7453-0.04106 \times \text { Age }+0.004477 \times \text { Age } \\
& \times \text { Age }+0.00014098 \times \text { Height }(\text { in } \mathrm{cm}) \\
& \times \text { Height (in } \mathrm{cm}) \\
& \text { Predicted } \mathrm{FEV}_{1} \text { men, age 20+ } \\
& =0.5536-0.01303 \times \text { Age }-0.000172 \times \text { Age } \\
& \times \text { Age }+0.00014098 \times \text { Height }(\text { in } \mathrm{cm}) \\
& \times \text { Height (in } \mathrm{cm}) \\
& \text { Predicted } \mathrm{FEV}_{1} \text { women } \\
& =0.4333-0.00361 \times \text { Age }-0.000194 \times \text { Age } \\
& \times \text { Age }+0.00011496 \times \text { Height }(\text { in } \mathrm{cm}) \\
& \times \text { Height (in } \mathrm{cm})
\end{aligned}
$$

Change in trough $\mathrm{FEV}_{1}$ (L) compared with no longacting treatment for each maintenance treatment was used to increase $\mathrm{FEV}_{1}$ upon initiation of treatment and thus patients on maintenance treatment remained in less severe health states longer than patients on no long-acting treatment. The changes in trough $\mathrm{FEV}_{1}$ (at 24 hours) for umeclidinium/ vilanterol (UMEC/VI) compared with tiotropium were

\begin{tabular}{|c|c|c|c|c|c|c|c|c|c|}
\hline \multirow[t]{2}{*}{ From } & \multicolumn{9}{|l|}{ To } \\
\hline & Mild base & Moderate base & Severe base & $\begin{array}{l}\text { Very severe } \\
\text { base }\end{array}$ & New moderate & New severe & $\begin{array}{l}\text { New very } \\
\text { severe }\end{array}$ & CV death & Death \\
\hline Mild base & - & & & & - & & & & - \\
\hline Moderate base & & 0.944 & & & & 0.031 & & & 0.026 \\
\hline Severe base & & & 0.922 & & & & 0.030 & & 0.048 \\
\hline Very severe base & & & & 0.952 & & & & & 0.048 \\
\hline New moderate & & & & & 0.948 & 0.026 & & & 0.026 \\
\hline New severe & & & & & & 0.909 & 0.043 & & 0.048 \\
\hline New very severe & & & & & & & 0.952 & & 0.048 \\
\hline Death & & & & & & & & 0.000 & 1.000 \\
\hline
\end{tabular}
obtained from the three clinical studies, and the estimate of change in trough $\mathrm{FEV}_{1}$ for no long-acting beta-2 agonist treatment was taken from GSK study DB113373, which compared UMEC/VI with a no-treatment arm where short-acting maintenance was allowed to treat short-term symptoms. Transition probabilities in years subsequent to year 1 were adjusted based on increased risk of death due to age.

The "moderate base" case represents transition probabilities of patients at the start of the model, in the context of their improvements in $\mathrm{FEV}_{1}$, which would be specific to their therapy regimen. The "moderate new" case, on the other hand, represents transition probabilities for patients newly transitioned into a given health state during the course of the

Table SI Transition probabilities for UMEC/VI

Abbreviations: CV, cardiovascular; UMEC/VI, umeclidinium/vilanterol. 
Table S2 Transition probabilities for tiotropium bromide

\begin{tabular}{|c|c|c|c|c|c|c|c|c|c|}
\hline \multirow[t]{2}{*}{ From } & \multicolumn{9}{|l|}{ To } \\
\hline & Mild base & Moderate base & Severe base & $\begin{array}{l}\text { Very severe } \\
\text { base }\end{array}$ & New moderate & New severe & $\begin{array}{l}\text { New very } \\
\text { severe }\end{array}$ & CV death & Death \\
\hline Mild base & - & & & & - & & & & - \\
\hline Moderate base & & 0.936 & & & & 0.038 & & & 0.026 \\
\hline Severe base & & & 0.911 & & & & $0.04 I$ & & 0.048 \\
\hline Very severe base & & & & 0.952 & & & & & 0.048 \\
\hline New moderate & & & & & 0.948 & 0.026 & & & 0.026 \\
\hline New severe & & & & & & 0.909 & 0.043 & & 0.048 \\
\hline New very severe & & & & & & & 0.952 & & 0.048 \\
\hline Death & & & & & & & & 0.000 & 1.000 \\
\hline
\end{tabular}

Abbreviation: $\mathrm{CV}$, cardiovascular.

Table S3 Transition probabilities for open dual LAMA + LABA

\begin{tabular}{|c|c|c|c|c|c|c|c|c|c|}
\hline \multirow[t]{2}{*}{ From } & \multicolumn{9}{|l|}{ To } \\
\hline & Mild base & Moderate base & Severe base & $\begin{array}{l}\text { Very severe } \\
\text { base }\end{array}$ & New moderate & New severe & $\begin{array}{l}\text { New very } \\
\text { severe }\end{array}$ & CV death & Death \\
\hline Mild base & - & & & & - & & & & - \\
\hline Moderate base & & 0.944 & & & & 0.031 & & & 0.026 \\
\hline Severe base & & & 0.922 & & & & 0.030 & & 0.048 \\
\hline Very severe base & & & & 0.952 & & & & & 0.048 \\
\hline New moderate & & & & & 0.948 & 0.026 & & & 0.026 \\
\hline New severe & & & & & & 0.909 & 0.043 & & 0.048 \\
\hline New very severe & & & & & & & 0.952 & & 0.048 \\
\hline Death & & & & & & & & 0.000 & 1.000 \\
\hline
\end{tabular}

Abbreviations: CV, cardiovascular; LABA, long-acting $\beta_{2}$-agonist; LAMA, long-acting muscarinic antagonist.

Table S4 Transition probabilities for no long-acting bronchodilator

\begin{tabular}{|c|c|c|c|c|c|c|c|c|c|}
\hline \multirow[t]{2}{*}{ From } & \multicolumn{9}{|l|}{ To } \\
\hline & Mild base & Moderate base & Severe base & $\begin{array}{l}\text { Very severe } \\
\text { base }\end{array}$ & New moderate & New severe & $\begin{array}{l}\text { New very } \\
\text { severe }\end{array}$ & CV death & Death \\
\hline Mild base & - & & & & - & & & & - \\
\hline Moderate base & & 0.925 & & & & 0.0490 & & & 0.026 \\
\hline Severe base & & & 0.890 & & & & 0.062 & & 0.048 \\
\hline Very severe base & & & & 0.952 & & & & & 0.048 \\
\hline New moderate & & & & & 0.948 & 0.026 & & & 0.026 \\
\hline New severe & & & & & & 0.909 & 0.043 & & 0.048 \\
\hline New very severe & & & & & & & 0.952 & & 0.048 \\
\hline Death & & & & & & & & 0.000 & 1.000 \\
\hline
\end{tabular}

Abbreviation: $\mathrm{CV}$, cardiovascular. 
model time horizon. Since these probabilities are not specific to a given drug, the values are the same for all drugs.

\section{References}

1. Spencer M, Briggs AH, Grossman RF, Rance L. Development of an economic model to assess the cost effectiveness of treatment interventions for chronic obstructive pulmonary disease. Pharmacoeconomics. 2005;23(6):619-637.
2. Hankinson JL, Odencrantz JR, Fedan KB. Spirometric reference values from a sample of the general US population. Am J Respir Crit Care Med. 1999;159(1):179-187.

\section{Publish your work in this journal}

The International Journal of COPD is an international, peer-reviewed journal of therapeutics and pharmacology focusing on concise rapid reporting of clinical studies and reviews in COPD. Special focus is given to the pathophysiological processes underlying the disease, intervention programs, patient focused education, and self management protocols.

\section{Dovepress}

This journal is indexed on PubMed Central, MedLine and CAS. The manuscript management system is completely online and includes a very quick and fair peer-review system, which is all easy to use. Visit $\mathrm{http} / / / \mathrm{www}$.dovepress.com/testimonials.php to read real quotes from published authors. 